Sonja Poulsen

\title{
The BBI Combinatory Dictionary of English: A Guide to Word Combinations. Compiled by Morton Benson, Eve- lyn Benson and Robert Ilson. John Benjamins Publishing Company/Munksgaards Ordbøger, Amsterdam/Philadel- phia 1986.
}

\section{Introduction}

A dictionary specializing in the presentation of the idiosyncratic word combinations or collocations of current English is a welcome innovation and potentially a very useful tool for language production. - Although the need to include collocations in general-purpose dictionaries is increasingly recognized, such dictionaries are always up against problems of space. Consequently, collocations are mostly relegated to the example material, and therefore only shown on a very selective basis.

Especially foreign learners are likely to benefit from a comprehensive dictionary of collocations, which will help them avoid translating word combinations from their own language directly, thereby violating the usage restrictions of the target language.

In the following I will look at the word combinations included in the BBI and the typology on which it is based, but since the BBI is not the first dictionary of English word combinations, I will begin by saying a few words about its predecessors

\section{Predecessors of the BBI}

One is the "Dictionary of English Style" published in 1961 by Prof. Dr Albrecht Reum from Leipzig in co-operation with A.H.J. Knight, Trinity College, Cambridge. Its aim was not much different from that of the BBI: it was meant to help young Germans produce genuine texts in English without formulating them in German first:

"Es ist sein vornehmstes Ziel, den Aufsatz- bzw. Briefschreiber dazu zu erziehen, statt seine Gedanken deutsch zu formulieren und dann ins Englische zu übertragen, gleich in englischen Denk- und Satzformen niederzuschreiben."

The dictionary concentrated on the vocabulary of "a contemporary, educated Englishman" (approx. 10,000 words) and, in addition to explana- 
tions (in German), synonyms and antonyms, extensive information was given about the combinations in which the words were found:

"Das Stilwörterbuch ... versucht in engem Rahmen einen Begriff davon zu geben, wie die Wörter ... im Zusammenhang der Rede gegenwärtig verwendet werden, in welchen Bedeutungen sie heute noch eine Rolle spielen, von welchen Attributen, Prädikaten und Adverbialien begleitet sie dem englischen Volke von heute geläufig und in welchen sprichwörtlichen Wendungen sie ihm vertraut sind."

Another dictionary of English word combinations, "The Word Finder" compiled and edited by J.l. Rodale — was first published as early as 1947. The aim of "The Word Finder" was totally different from that of Reum's "Dictionary of Style" Although it contained long lists, e.g. of adjectives and verbs to be combined with a given noun, or adverbs to go with a certain verb, the idea was not to enable ordinary users to produce typical collocations, but to help young writers in their literary aspirations. Consequently, it did not include many of the recurrent combinations that are now normally referred to as collocations. Nevertheless, the dictionary was recommended to Danish students of English even in the 1970s.

According to the foreword to the seventeenth printing, 1965, "only words that are evocative, that stimulate and unfurl the wings of the imagination, are of real assistance to the aspiring writer" As an illustration, the foreword showed how the simple thought expressed in "His cheerful character charmed me very much" can be "more sumptuously expressed" by means of the dictionary: "His piquant charm was of a perplexingly elusive character, haunting, subtle, yet its very intensity was irresistible" (!)

Without questioning the sincerity of the editors of "the Word Finder", who "trust that all students of this book will succeed in sending winged words on far-flung odysseys to Fame", I think that most students of English will be content to find that the aims of the BBI are closer to those expressed by Albrecht Reum.

Finally, I would like to mention The Oxford Dictionary of Current Idiomatic English (ODCIE). The first volume, published in 1975, contains verbs with prepositions and particles. It shows the collocational patterns of the verb entries in a very comprehensive and consistent way and, although it is narrower in scope than the BBI, it may serve as a standard of comparison.

\section{The scope and typology of the BBI}

The aim of the BBI is to give "essential grammatical and lexical recurrent word combinations, often called collocations". It does not include id- 
ioms like to kill two birds with one stone, which are defined as frozen expressions in which the meaning of the whole does not reflect the meaning of the component parts. However, it does include some phrases that lie between collocations and idioms, in that the meaning of the component parts are reflected partially in the meaning of the whole. Such expressions are mainly similes like free as a bird and sweet as sugar, but also fixed phrases like to mix business with pleasure. The BBI specifically excludes free combinations, which are defined as combinations that "consist of elements that are joined in accordance with the general rules of English syntax and freely allow substitution" (Introduction, ix). Furthermore, free lexical combinations are described as "those in which the two elements do not repeatedly co-occur, the elements are not bound specifically to each other; they occur with other items freely" (Introduction, xxiv).

The typology of the BBI can be illustrated as follows (the types of word combination included in the dictionary are underlined):

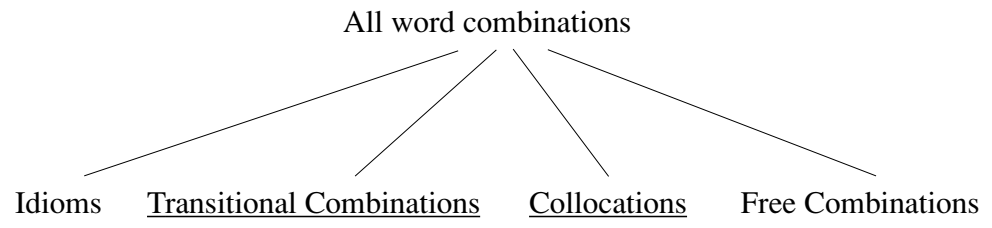

Grammatical Collocations $\quad$ Lexical Collocations

It is worth noting that there is no transitional category between collocations and free combinations to parallel that between collocations and idioms. The failure to address the problems of demarcation involved results in some vacillation as to whether certain types of combination should be included or not (see 3.1 and 3.2 below).

As regards the scope of the BBI in terms of areas of language covered, the dictionary attempts "to give only the most commonly used lexical collocations" (Introduction, xxvi). According to the Introduction, collocations that are used only in technical language (used in the sense of LSP) are not normally included - on the other hand, the dictionary does give "some technical collocations that will be of interest to students and teachers of English for special purposes". - Considering the size of the dictionary, it is quite impressive how many LSP collocations are included, 
but, on the other hand, users looking for a specific combination will often consult the dictionary in vain. Combinations like file an affidavit and lodge an appeal can be looked up, but it is not possible to find balance sheet and bill of exchange and the verbs used about the "creation" of these documents (draw up a balance sheet and draw a bill of exchange on somebody)

\subsection{Grammatical collocations}

Collocation is normally seen as a lexical phenomenon although it occurs within the framework of syntax and may itself be subject to lexicogrammatical restrictions. However, the BBI uses the concept of grammatical collocation, defined as a phrase consisting of a dominant word (noun, adjective, verb), and a preposition or grammatical structure such as an infinitive or clause. The reason for including combinations with prepositions in a special category is that they are categorized as "grammatical words" (Benson 1985: 61). - The same reasoning is not applied to combinations with delexical or "empty" verbs like make, do and have, which also have grammatical functions, and I think that it is debatable whether a new category is required to accommodate prepositions.

Extending the concept of collocation to include combinations between a lexical item and a grammatical structure (irrespective of the lexical items it contains) does call for a new concept, however. The grammatical structures are subject to usage restrictions connected with specific lexical items and the patterns found here (e.g. verb patterns) belong to an area that may be said to lie between grammar and lexis.

Such information can also be found in general-purpose dictionaries and, in a dictionary of word combinations, it might have been preferable to leave it out in order to be able to show lexical collocations (including combinations with prepositions) on a more comprehensive scale.

However, it may also be argued that, because of their idiosyncratic nature, grammatical patterns of this kind are complementary to lexical collocations and that it is therefore natural to include them. At any rate, the patterns are described in a very user-friendly way with examples, possible alternatives and usage notes as well as by means of a coding system referring to the introductory notes.

The choices made as to which types of combination to include are accounted for in the Introduction, the main principle being that structures which can be produced by using the general rules of grammar do not belong in the dictionary. - Although this seems to be a sound principle, it 
may cause problems, which can be seen from the examples given in the Introduction to illustrate noun + preposition combinations. The authors say that they are going to include the combination blockade against, but not blockade of, since the latter is a regular transformation of a verb + object structure: to blockade enemy ports the blockade of enemy ports. However, the two prepositional phrases are alternatives that fulfil the same lexical function:

$$
\text { the blockade } \begin{aligned}
& \text { of } \\
& \text { against enemy ports }
\end{aligned}
$$

To give only one possibility is misleading, because it gives the user the wrong impression that only blockade against is acceptable.

The combinations with apathy also given as examples do not pose the same problems. Apathy of as in the apathy of the electorate, is not an alternative to apathy towards as in his apathy towards the poverty of the people.

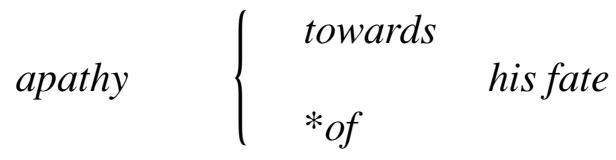

In other words it does not have the same lexical function and excluding it from the dictionary will not mislead users into believing that it is unacceptable as an alternative to the genitive construction.

A category of "open collocations" between collocations and free combinations would make it possible to include blockade of without including apathy of.

\subsection{Lexical collocations}

Lexical collocations are defined in contrast to grammatical collocations as normally not containing prepositions, infinitives or clauses and typically consisting of nouns, adjectives, verbs and adverbs (Introduction, xxiv).

Seven types of lexical collocation are included, five of which are accounted for by combinations with nouns: three are combinations of nouns and verbs, one covers adjective plus noun combinations, including compounds with an adjectival noun as the first element, and a further type gives the unit associated with a given noun. The two remaining types of collocation are combinations of adverbs and adjectives and of verbs and adverbs, respectively. 
Morton Benson has described lexical collocations as usually consisting of two "equal" lexical components - in contrast to grammatical collocations (Benson 1985: 62), but this principle of equality is not reflected in the BBI. Generally combinations with nouns are found in noun entries, so that in practice a hierarchical relationship is assumed between the constituent elements. From the point of view of language production this is much to be preferred (Cp. Hausmann 1985: 119). Collocations are syntagmatic combinations with a main element, or base, which is determined by another, secondary element and it is natural for users to look up a noun to find the verbs, adjectives or prepositions to go with it, not the other way round. Verbs and adjectives are only relevant as base items in collocations with adverbs and prepositions (or in grammatical collocations including infinitives or clauses). - A practical advantage of this hierarchical view is that it saves a lot of space in the dictionary.

The different types of lexical collocation are based on the concept of lexical functions, which was introduced by Apresyan, Mel'cuk and Zolkovsky (Apresyan et al. 1969) working on a new type of dictionary called "The Explanatory and Combinatory Dictionary of Modern Russian".

A standard lexical function was defined as follows

A standard lexical function is a meaning relation between a key word (or word combination) $C_{0}$ and other words and word combinations $C_{i}$, which meets the following three requirements:

(1) this relation occurs in a sufficiently great number of word pairs, i.e. it manifests itself through many different $C_{0}$

(2) this relation has diverse means of expression, i.e. the number of different $C_{i}$ in the language is rather great

(3) the choice of the right $C_{i}$ for the expression of a given relation with a given $C_{0}$ is determined, as a rule, by the $C_{0}$ itself (sometimes under supplementary conditions)

The authors identified no less than 47 standard lexical functions, which were given Greek- and Latin sounding names, plus a number of individual functions that could not be accommodated in the standard list.

The BBI has chosen to focus on a limited number of lexical functions, some of which do however, cover several of the functions identified by Apresyan et al. (1969). In one type of collocation the verb thus denotes the function creation and or activation (inflict a wound, run a test), in a second type the function is eradication and or nullification as in lift blockade. Further functions express characteristic action (silence reigns) or high degree( 
cutthroat competition, deeply absorbed, effect deeply) and, collocations indicating the unit associated with a noun constitute a final function ( $a$ piece of advice an act of violence, etc.).

The failure to address the problems of demarcation between collocations and free combinations was seen in the combinations of nouns and prepositions (cp. the examples with blockade mentioned above), but is even more evident from the vacillation about which combinations to include under the different lexical functions. - According to the Introduction (xxv) many combinations with verbs such as build, cause, cook, grow, manufacture etc. are considered to be free combinations and are therefore excluded although they belong to the lexical function "creation and or activation". It gives the following examples of such free combinations, which are found to be "predictable on the basis of the meaning of their constituent elements":

\section{build bridges (houses, roads) cause damage (deafness, a death) cook meat (potatoes, vegetables)}

However, it seems that the authors are not altogether satisfied with the criterion of "predictability" since, nevertheless, five of these nine "free combinations" are included in the dictionary (build a bridge/house; cause damage/death,; cook meat). Although, cook vegetables is not included, cooked vegetables is, and whereas cook potatoes has been left out, bake potatoes is included.

I think these inconsistencies are attribuable to a rather vague definition of collocations ("essential grammatical and lexical recurrent word combinations ") and more specifically to the failure to distinguish between free combinations and "open collocations". From a decoding point of view, such collocations may well be predictable on the basis of the meaning of their constituent elements, but for encoding purposes they have to be included if they express a lexical function central to the meaning or use of a given lexical item.

This is especially necessary if they belong to a set of alternative expressions and leaving them out would give users the wrong impression that they had better be avoided, as in the examples of combinations with blockade given earlier. (Cp. Hausmann 1979: 193). Leaving out cause from the set of alternative verbs collocating with damage would therefore have been a mistake: 


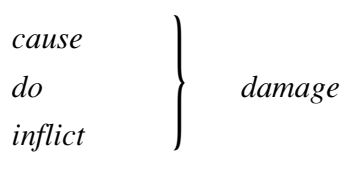

It is therefore fortunate that, in spite of its declared intentions, the BBI does give many such "open collocations", but less fortunate that it does not do so consistently. Thus the entry for inflation gives.control and curb as possible collocates, but not the combination reduce inflation which is presumably no less frequent. (In a citation bank including 1000 combinations with inflation, reduce inflation occurred 15 times, curb inflation 10 times, and control inflation 7 times; cp Poulsen 1991: 75). By comparison, the entry for unemployment includes reduce.without any alternatives.

A further aspect is that the most open collocations also tend to be the most neutral ones from a stylistic point of view, so that leaving them out will lead to a misrepresentation of the collocational range of an item, in that the unmarked level of formality will be missing.

To present users with a comprehensive choice, I think it is necessary to decide what lexical functions are relevant in the case of individual items and then to show the full range of alternatives in each case, including open as well as more restricted collocations. At least a distinction should be made between open sets of collocates to which other words can be freely added, and sets that virtually exhaust the possible range of combinations. In the ODCIE, Vol. 1, a warning sign ( $L$ ) precedes sets that represent a severely limited range of choice (Introduction to the ODCIE 6.5).

This would prevent the rather incomplete and uneven treatment of items which I have found in a number of entries. Thus the entry for injunction includes issue but not serve an injunction on sby, whereas the entry for writ includes issue as well as serve. The entry for bill (statement of money owed) gives many relevant collocations, but not make out a bill, although the lexical function of "creation" is considered to be important. Deficit is in the dictionary, but to run a deficit is not. The entry for business at first glance seems quite comprehensive, but in the sense of "firm" it gets only a few lines — and not a word about "business failure" or "going to the wall" although this expresses the function of "eradication and/or nullification".

\section{Concluding remarks}

As will appear from the above comments on the BBI, I do not think it quite lives up to what one might expect from a specialized dictionary of collocations, namely that it should present users with a truly comprehen- 
sive range of alternative collocates expressing the lexical functions required in the case of individual items.

This results in a number of "gaps" where relevant lexical functions are not included or are not fully represented. A special problem is the failure to address the problem of demarcation between collocations and free combinations. This leads to ,insistencies in the treatment of "open collocations", which lie between the two, and may give users a wrong impression of the collocational range of a given item.

In spite of the critical remarks about the BBI, I still think it deserves much credit for its functional approach to word combinations, which are represented in a user-friendly way and on a much more comprehensive scale than is found in general purpose dictionaries. - At any rate, a dictionary like the BBI with its focus on recurrent word combinations is a vast improvement on the "winged words" of the Word Finder, which my generation of students had to resort to.

\section{Literature}

Apresyan, Yu.D. / I.A. Mel'cuk / A.K. Zolkovsky (1969): Semantics and Lexicography: Towards a new type of unilingual dictionary, in F.Kiefer (ed.):Studies in syntax and semantics. Dordrecht, Holland: D. Reidel 1969, 1-33.

Benson, Morton (1985): Collocations and Idioms, in: C.J. Brumfitt (General Editor): Dictionaries, Lexicography and Language Learning. Pergamon Press in association with the British Council, 1985.

Benson, Morton / Evelyn Benson / Robert Ilson (1986): Lexicographic Description of English. Studies in Language Companion Series, Vol. 14, Amsterdam/Philadelphia: John Benjamins Publishing Company 1986, 252-262.

Cowie, A.P., et al (1975): The Oxford Dictionary of Current Idiomatic English, Volume 1, Oxford: Oxford University Press 1975.

Hausmann, Franz Joseph (1979): Un dictionnaire de collocations est-il possible? Travaux de linguistique et litterature 17, Centre de philologie et de litteratures romances de l'université de Strasbourg 1979, 187-195.

Poulsen, Sonja (not published): Word Combinations as Lexical Building Blocks. A theoretical framework and a possible concept for a specialized dictionary of English collocations for text production.

Reum, Albrecht (1961): A Dictionary of English Style, München: Max Hueber Verlag 1961.

Rodale, J.1. (1965): The Word Finder. Emmaus, Pennsylvania: Rodale Books, Inc.1947. 
